\title{
Multidrug-resistant tuberculosis in Alberta and British Columbia, 1989 to 1998
}

\author{
Ahmed Hersi $M D^{1}$, Kevin Elwood $\mathrm{MD}^{3}$, Robert Cowie $\mathrm{MD}^{2}$, Dennis Kunimoto $\mathrm{MD}^{1}$, \\ Richard Long $\mathrm{MD}^{1}$ \\ Departments of Medicine, University of Alberta and University of Calgary; \\ British Columbia Centre for Disease Control
}

A Hersi, K Elwood, R Cowie, D Kunimoto, R Long. Multidrug-resistant tuberculosis in Alberta and British Columbia, 1989 to 1998. Can Respir J 1999;6(2):155-150.

OBJECTIVE: To describe the extent of the problem of multidrug-resistant tuberculosis (MDR-TB) in Alberta and British Columbia from 1989 to 1998.

DESIGN: A retrospective, population-based descriptive study of all notified MDR-TB cases in the context of all notified TB cases, all notified culture-positive TB cases and all notified drug-resistant TB cases.

SETTING: Provinces of Alberta and British Columbia, and their TB registries.

PATIENTS: All people with TB reported to the TB registries of Alberta and British Columbia between January 1, 1989 and June 30, 1998.

MAIN OUTCOME MEASURES: Drug susceptibility testing was performed in all cases of culture-positive TB. Demographic, clinical and laboratory data on all cases of MDR-TB were recorded.

RESULTS: Of 4606 notified cases of TB, 3553 (77.1\%) were culture positive. Of these, $365(10.3 \%)$ were drug resistant; of the drug-resistant cases, 24 (6.6\%) were MDR. Most MDR-TB patients were foreign-born; of the four Canadianborn patients, two were infected while travelling abroad. Although foreign-born patients were significantly more likely to harbour drug-resistant strains, $14.3 \%$ versus $4.8 \%$, respectively $(\mathrm{P}<0.001)$, among those who were harbouring a drug-resistant strain, the proportion of Canadian-born versus foreign-born patients with an MDR strain was the same (6.7\% versus $6.6 \%$, respectively). From 1994 to 1998 versus 1989 to 1993, the proportion of all drug-resistant strains that were MDR was greater ( $9.0 \%$ versus $4.3 \%$, respectively), but the difference was not statistically significant. Isolates from 16 of the 24 MDR-TB cases had been archived. Each of these was fingerprinted and found to be unique. Most MDR-TB cases $(88 \%)$ were respiratory. Of those tested for human immunodeficiency virus $(\mathrm{n}=17)$, only one was seropositive. MDR-TB was 'acquired' in $67 \%$ and 'primary' in $33 \%$ of cases. Eight (33\%) of the MDR-TB cases received curative courses of treatment, six $(25 \%)$ are still being treated, and the remainder have either died (five, 21\%), transferred out (four, 17\%) or become 'chronic' (one, 4\%). No secondary case of MDR-TB has been identified in Alberta and British Columbia.

CONCLUSIONS: Most MDR-TB in Alberta and British Columbia is imported. The proportion of all drug-resistant cases that are MDR appears to be increasing, but not because of disease acquired from recent contact with MDR-TB in Canada.

Key Words: DNA fingerprint, Population study, Tuberculosis

\section{Tuberculose multirésistante en Alberta et en Colombie-Britannique de 1989 à 1998}

OBJECTIF : Décrire l'ampleur du problème de multirésistance aux agents antituberculeux en Alberta et en Colombie-Britannique de 1989 à 1998.

voir page suivante

Correspondence and reprints: Dr Richard Long, Department of Medicine, Division of Pulmonary Medicine, University of Alberta Hospitals, Room 2E4.21, Walter Mackenzie Centre, 8440 - 112 Street, Edmonton, Alberta T6G 2B7. Telephone 780-407-7551, fax 780-407-6384, e-mail richard.long@health.gov.ab.ca 
MODÈLE : Étude descriptive et rétrospective basée dans la population de tous les cas déclarés de TB multirésistante dans le contexte de tous les cas déclarés de TB, de tous les cas de TB à culture positive et de tous les cas déclarés de résistance aux antituberculeux.

CONTEXTE : Provinces de l'Alberta et de la Colombie-Britannique, et leurs registres de la tuberculose.

PATIENTS : Toutes les personnes atteintes de tuberculose déclarées aux registres de la tuberculose de l'Alberta et de la Colombie-Britannique entre le $1^{\text {er }}$ janvier 1989 et le 30 juin 1998.

PRINCIPALES MESURES DES RÉSULTATS : Un test de sensibilité aux médicaments a été pratiqué dans tous les cas de TB à culture positive. Les données démographiques, cliniques et de laboratoire sur tous les cas de multirésistance aux antituberculeux ont été consignées.

RÉSULTATS : De 4606 cas déclarés de TB, 3553 (77,1\%) étaient positifs à la culture. De ceux-là, $365(10,3 \%)$ étaient résistants aux antituberculeux ; des cas de TB résistante, 24 (6,6\%) étaient multirésistants. La plupart des cas de multirésistance concernait des personnes nées à l'étranger ; des quatre cas concernant des personnes nées au Canada, deux avaient été infectées pendant un voyage à l'étranger. Bien que les personnes nées à l'étranger démontrent une plus forte probabilité d'être porteuses de souches résistantes, $14,3 \%$ par rapport à $4,8 \%(\mathrm{p}<0,001)$, parmi celles qui étaient por- teuses d'une souche multirésistante, la proportion des personnes nées au Canada par rapport à celles nées à l'étranger et infectées par une souche multirésistante était la même $(6,7 \%$ par rapport à 6,6\%). De la période allant de 1994 à 1998 par rapport à celle allant de 1989 à 1993, la proportion de toutes les souches résistantes qui étaient multirésistantes était supérieure $(9,0 \%$ par rapport à 4, $3 \%)$, mais cette différence n'avait pas de signification statistique. Les isolats de 16 des 24 cas de TB multirésistante avaient été archivés. Chacun de ces isolats a été testé par cartographie génétique et déclaré unique. La plupart des cas de multirésistance étaient des cas respiratoires. De ceux testés pour le virus de l'immunodéficience humaine ( $\mathrm{n}=17)$, un seul cas était séropositif. La TB multirésistante était acquise dans $67 \%$ des cas, et primaire dans $33 \%$ des cas. Huit (33\%) des cas de TB multirésistante ont reçu un traitement curatif, six (25\%) sont en cours de traitement. Le reste des personnes atteintes sont décédées (cinq, $21 \%$ ), ont été transférées (quatre, $17 \%$ ) ou bien sont des cas chroniques (un, $4 \%$ ). Aucun cas secondaire de TB multirésistante n'a été identifié en Alberta ou en Colombie-Britannique.

CONCLUSIONS : En Alberta et en Colombie-Britannique, la plupart des cas de multirésistance aux antituberculeux sont importés. La proportion de tous les cas résistants qui sont aussi multirésistants semble progresser, mais pas à cause d'une maladie acquise au Canada d'un récent contact avec une TB multirésistante.
$\mathrm{W}$ orldwide, the proportion of all cases of tuberculosis (TB) due to drug-resistant strains is increasing (1). In Canada, the prevalence of TB due to isolates resistant to one or more first-line anti-TB drugs remained unchanged from $1978(9.3 \%)$ to 1993 (8.7\%) (2; E Farzad, Laboratory Centre for Disease Control, Ottawa, Ontario, personal communication). However, the most recent drug-resistance surveys in Canada (E Farzad, personal communication; 3-6) suggest regional differences in the prevalence of resistance as well as risk factors for resistance. For example, resistance rates were higher in Montreal $(16.2 \%)$ than they were nationally $(8.7 \%)$ or in western Canada (6.9\%) or Manitoba (6.4\%) (E Farzad, personal communication; 3-5), and being foreign-born was associated with a significantly increased risk of harbouring a drug-resistant strain in western Canada $(4,5)$, but not nationally (E Farzad, personal communication) or in Montreal (3).

Another difference concerns the proportion of all drugresistant strains that were multidrug resistant (MDR). In the two surveys involving western Canadian populations $21.4 \%$ and $10.8 \%$ of resistant strains were MDR $(4,5)$, whereas, in Montreal and nationally, the proportions were $8.5 \%$ and $7.5 \%$, respectively (E Farzad, personal communication; 3). In large urban centres of the United States, particularly those with a high prevalence of human immunodeficiency virus (HIV), MDR-TB has been a major problem, compromising both treatment and control programs (7). To date, no Canadian data specifically address the problem of MDR-TB. In the present study, we undertook to analyze all notified MDR-TB cases in the provinces of Alberta and British Columbia between 1989 and 1998. Together, these western Canadian provinces accept approximately one-third of all new immigrants to Canada. The ethnic origin of the patients with TB are very similar (approximately $60 \%$ foreign born, $20 \%$ Aboriginal and the balance Canadian born, non-Aboriginal), and there is little that separates the conduct of the provinces'
TB control programs. HIV-TB comorbidity has been reported in Vancouver (8).

We were particularly interested in whether MDR-TB was 'acquired' (through multiple ineffectual courses of treatment with various drugs) or 'primary' (due to transmission of MDR strains to contacts), as has been reported in the United States (8).

\section{PATIENTS AND METHODS}

All cases of active TB diagnosed in residents of Alberta and British Columbia between January 1, 1989 and June 30, 1998 were identified in the central TB registry of each province. Cases were categorized as being culture positive or negative for Mycobacterium tuberculosis complex, and culture-positive cases were further categorized as being drug resistant or drug susceptible, through the records of the provincial laboratories. Drug-resistant cases that were resistant to isoniazid (INH) and rifampin (RIF), with or without resistance to other drugs, were defined as multidrug-resistant (MDR-TB).

Demographic, clinical and mycobacteriological data on all cases of MDR-TB were extracted from the tuberculosis registries and provincial laboratories in each province, as well as from the individual medical records.

Demographic data: Age at diagnosis, sex and location of birth, Canadian born or foreign born, were recorded. For foreign-born patients, the country of birth, World Health Organization region of birth, date of arrival in Canada, immigration status (Canadian citizen, landed immigrant, visitor permit, work permit, refugee claimant or student) and surveillance referral status were also noted. Surveillance referrals refer to those individuals applying for immigration to Canada, who have been identified during processing as being at risk for reactivation of $\mathrm{TB}$, and are, therefore, targeted for postlanding surveillance in Canada. 
TABLE 1

Birthplace of patients with tuberculosis (TB) reported in Alberta and British Columbia (1989 to 1998)

\begin{tabular}{lcccc}
\hline & & Birthplace & & \\
Cases & Canadian-born (\%) & Foreign-born (\%) & Birthplace unknown (\%) & Total (\%) \\
\hline All TB & $1714(37)$ & $2683(58)$ & $209(5)$ & $4606(100)$ \\
Culture-positive TB & $1254(35)$ & $2128(60)$ & $171(5)$ & $3553(100)$ \\
Drug-resistant TB & $60(6)$ & $305(84)$ & 0 & $365(100)$ \\
Multidrug-resistant TB & $4(17)$ & $20(83)$ & 0 & $24(100)$ \\
\hline
\end{tabular}

Clinical data: For each case, the date of diagnosis (date on which the case was reported to the tuberculosis registry), type of disease (respiratory smear positive, respiratory smear negative or nonrespiratory) and disease status (new active disease or relapse) were recorded according to the Canadian Tuberculosis Reporting System, Laboratory Centre for Disease Control, Ottawa, Ontario. A new active case is a case not previously reported. A relapse is a recurrence of active disease in the same patient after a known period of inactivity.

MDR-TB patients were classified as having 'primary' drug resistance (resistance to strains of $M$ tuberculosis complex in patients without histories or other evidence of previous treatment) or 'acquired' drug resistance (resistance in a patient who had previously received antituberculous treatment for at least one month, including those with treatment failure and relapses).

The following details of the management were noted.

- Outcome (cured, died, transferred out, other). For patients who were cured, the duration of treatment was recorded. For all patients, the duration of hospitalization and the use of resectional surgery for respiratory disease was noted. For patients who died, TB was recorded as the primary, contributory or noncontributory cause of death.

- Time to culture conversion. The time from the start date of treatment in cases that were MDR on the initial isolate until the first negative culture beyond which all further cultures were negative was recorded.

- Contact follow-up. The total number of contacts (casual, close or unknown) investigated, their tuberculin status (positive-converter, positive-no past tuberculin test, negative, unknown), the number of secondary cases among contacts and the number of contacts prescribed prophylaxis were noted.

Laboratory data: Isolates were processed with the radiometric system (BACTEC 460, Becton-Dickinson Diagnostic Instrument Systems, Maryland). Details of this method have been described previously (5). In each provincial mycobacterial laboratory, the BACTEC system had been validated against the proportion method used by the Laboratory Centre for Disease Control. Susceptibilities to INH, RIF, ethambutol (EMB) and streptomycin (SM), and, in some cases (including all MDR-TB cases), pyrazinamide (PZA) were performed in duplicate with the radiometric method. Drug concentrations used were as follows: INH $0.1 \mu \mathrm{g} / \mathrm{mL}$, RIF $2.0 \mu \mathrm{g} / \mathrm{mL}$, EMB $7.5 \mu \mathrm{g} / \mathrm{mL}, \mathrm{SM} 6.0 \mu \mathrm{g} / \mathrm{mL}$ and PZA $100 \mu \mathrm{g} / \mathrm{mL}$.

Patients identified as being at risk for HIV infection (for the early years of this survey this did not include patients with a diagnosis of TB) were serotested (screening, ELISA and confirmatory test, Western blot antibody test) after informed consent was obtained (9). Appropriate pre- and post-test counselling was provided.

Available MDR-TB isolates were DNA fingerprinted by IS6110-based restriction fragment length polymorphism analysis (10) and compared using GELCOM PAR software (applied Maths, Ghent, Belgium). Phylogenetic analysis was performed by the unweighted pair-group method using arithmetic averages method using the Dice coefficient, based on the restriction pattern of all available MDR isolates (11).

Statistical analysis: Statistical differences in the proportion of patients with drug-resistant isolates were determined by $\chi^{2}$ test. Results were considered significant at $\mathrm{P}<0.05$.

\section{RESULTS}

Over the study period, 4606 cases of TB were diagnosed in residents of Alberta and British Columbia. Of these, 3553 (77.1\%) were culture positive. Among those who were culture positive, 365 (10.3\%) were drug resistant, and, among those who were drug resistant, 24 (6.6\%) were MDR (Table 1). The proportion of drug-resistant cases that were MDR was similar in Alberta (nine of 141, 6.4\%) and British Columbia (15 of 224, 6.7\%). All but three of those with MDRTB were residents of either Vancouver, Calgary or Edmonton.

Although foreign-born patients were significantly more likely to harbour drug-resistant strains than Canadian-born patients (305 of 2128 [14.3\%] versus 60 of 1254 [4.8\%], respectively, $\mathrm{P}<0.001$ ), among those who were harbouring a drug-resistant strain, the proportion of Canadian-born versus foreign-born patients with an MDR strain was the same (four of 60 [6.7\%] versus 20 of 305 [6.6\%]respectively). In this regard, however, it is important to note that of the four Canadian-born MDR-TB patients, two were infected while travelling abroad (one in Thailand, the other in Spain).

From 1994 to 1998 compared with 1989 to 1993, the proportion of all drug-resistant strains that were MDR was greater (16 of 178 [9.0\%] compared with eight of 187 [4.3\%], respectively), but the difference was not statistically significant $(\mathrm{P}=0.07)$. 
TABLE 2

\section{Immigration status of foreign-born multidrug-resistant-tuberculosis (TB) cases in Alberta and British Columbia (1989 to 1998)}

\begin{tabular}{|c|c|}
\hline Patient characteristic & Number of cases (\%) \\
\hline \multicolumn{2}{|c|}{ Immigration status at time of diagnosis } \\
\hline Canadian citizen & $4(20)$ \\
\hline Landed immigrant & $14(70)$ \\
\hline Visitor & $1(5)$ \\
\hline Immigrant applicant & $1(5)$ \\
\hline \multicolumn{2}{|l|}{ Surveillance referral ${ }^{*}$} \\
\hline Yes & $7(35)$ \\
\hline No & $13(65)$ \\
\hline \multicolumn{2}{|c|}{ Place of birth (World Health Organization region, country) ${ }^{*}$} \\
\hline \multicolumn{2}{|c|}{ Western Pacific region } \\
\hline China (includes Hong Kong) & $8(40)$ \\
\hline Philippines & $3(15)$ \\
\hline Vietnam & $1(5)$ \\
\hline South Korea & $1(5)$ \\
\hline \multicolumn{2}{|l|}{ Eastern Mediterranean region } \\
\hline Pakistan & $1(5)$ \\
\hline Somalia & $1(5)$ \\
\hline \multicolumn{2}{|l|}{ European region } \\
\hline Ireland & $1(5)$ \\
\hline Israel & $1(5)$ \\
\hline \multicolumn{2}{|l|}{ Southeast Asia region } \\
\hline India & $1(5)$ \\
\hline Myanmar & $1(5)$ \\
\hline \multicolumn{2}{|l|}{ African region } \\
\hline Ethiopia & $1(5)$ \\
\hline \multicolumn{2}{|c|}{ Time from arrival in Canada to diagnosis } \\
\hline Two years or less & $10(50)$ \\
\hline Two to five years & $4(20)$ \\
\hline More than five years & $6(30)$ \\
\hline
\end{tabular}

*Surveillance referrals are those individuals applying for immigration to Canada, who have been identified during processing as being at risk for reactivation of $T B$, and are, therefore, targeted for postlanding surveillance in Canada

Table 2 outlines the immigration status of all foreign-born MDR-TB cases. Most (90\%) were either Canadian citizens or landed immigrants, and a sizeable proportion $(35 \%)$ were surveillance referrals. Foreign-born MDR-TB patients were most likely to have emigrated from the western Pacific region $(65 \%)$ and to have arrived in Canada within the past five years $(70 \%)$. All but four arrived during the period of the study.

MDR-TB patients were all adult (average age 52 \pm 19 years), and three-quarters were male (Table 3). Of those tested for HIV ( $\mathrm{n}=17,50 \%$ of the MDR cases from 1989 to 1993, 81\% of the MDR cases from 1994 to 1998), only one was seropositive. Most patients (88\%) had respiratory TB, and, of these, 16 of $21(76 \%)$ were sputum smear-positive. Fourteen patients were reported as having 'relapsed' and 10 patients as having 'new active' disease. MDR was 'acquired' in two-thirds of the patients; both of the Canadian-born patients who were not infected while travelling abroad,
TABLE 3

Clinical and laboratory data on multidrug-resistant cases in Alberta and British Columbia (1989 to 1998)

\begin{tabular}{lc}
\hline Characteristic & $\begin{array}{c}\text { Number of cases } \\
(\%)\end{array}$ \\
\hline Age (years) & $8(33)$ \\
20 to 39 & $8(33)$ \\
40 to 59 & $8(33)$ \\
Older than 60 & \\
Sex & $18(75)$ \\
Male & $6(25)$ \\
Female & \\
Human immunodeficiency virus type 1 status & $1(4)$ \\
Positive & $16(67)$ \\
Negative & $7(29)$ \\
Unknown & \\
Disease type & $21(88)$ \\
Respiratory & $3(12)$ \\
Nonrespiratory & \\
Type of resistance & $8(33)$ \\
Primary & $16(67)$ \\
Acquired & \\
Resistance & $24(100)$ \\
Isoniazid & $24(100)$ \\
Rifampin & $7(29)$ \\
Pyrazinamide & $13(54)$ \\
Ethambutol & $12(50)$ \\
Streptomycin &
\end{tabular}

started with a fully drug susceptible isolate and, through drug malabsorption (a Treaty-status Aboriginal woman) and nonadherence (a Canadian-born, non-Aboriginal man) became MDR over time. MDR-TB strains were resistant to an average of 3.25 first-line drugs.

The outcome of the MDR-TB patients is given in Table 4. Eight $(33 \%)$ were cured with courses of therapy that lasted two or more years in each case, six others continue to be treated and one, a psychiatric patient who lives in relative isolation, refuses further treatment. Of the nine remaining patients, four transferred out of Alberta and British Columbia (all were transferred out on treatment; one to his country of origin, Israel, and three to Ontario. One of the latter went to the National Jewish Centre for Immunology and Respiratory Medicine in Denver, Colorado, for an extended course of treatment before moving to Ontario), and five died with TB as either the primary or a contributory cause of death. Resectional surgery was performed in four patients. The time to culture conversion averaged $134 \pm 162$ days (mean \pm SD; median 84 to 91 days) (patients who died or transferred out before culture conversion as well as those who have not yet converted, were nonrespiratory or who refused treatment $[\mathrm{n}=8]$ were excluded). The duration of hospitalization varied between 0 and 12 months, averaging three months.

Follow-up identified 727 contacts. Although only 10 contacts were demonstrated to have converted their tuberculin test, a large proportion of the contacts (266 or 37\%) had a 
positive tuberculin test with unknown converter status. No secondary case of MDR-TB has been reported in Alberta and British Columbia.

Of the 24 MDR $M$ tuberculosis complex strains, 23 were $M$ tuberculosis and one was Mycobacterium bovis (12). Fifteen of the 23 M tuberculosis strains had been archived. Each was DNA fingerprinted and found to be unique.

\section{DISCUSSION}

Over the study period, we found that $10.3 \%$ of the patients in Alberta and British Columbia with culture-positive TB had disease that was resistant to one or more first-line antituberculous drugs. Of those that were drug resistant, 24 (6.6\%) were multidrug-resistant. The proportion of drug-resistant strains that were MDR increased over the period of the study, from $4.3 \%$ in the first five years (1989 to 1993) to $9.0 \%$ in the last four and one-half years (1994 to June 30, 1998), but the difference was not statistically significant. Earlier surveys of antituberculous drug resistance in western Canadian populations $(4,5)$ suggested that the proportion of all resistant strains that were MDR was higher in western Canada than elsewhere (E Farzad, personal communication; 3). The present survey, however, found little difference between regions with respect to the proportion of all resistant strains that were MDR: $6.6 \%$ in Alberta and British Columbia; $7.5 \%$ in Montreal and $8.5 \%$ nationally (E Farzad, personal communication; 3).

Although foreign-born patients were significantly more likely to harbour drug-resistant strains than Canadian-born patients (14.3\% versus $4.8 \%$ ), among those who were harbouring a drug-resistant strain, the proportion of foreignborn versus Canadian-born patients with an MDR strain was the same (approximately 7\%). These numbers are somewhat misleading, however, because, of the four Canadian-born patients with MDR-TB, two acquired their infection while travelling abroad and the remaining two started with an isolate that was fully drug susceptible and, through drug malabsorption in one and nonadherence in another, became MDR over time. If, as is widely believed, most cases of TB in foreignborn patients result from reactivations of latent infection acquired in the immigrants' country of origin (13), every case in which MDR was reported on the initial isolate $(n=22)$ would appear to have been imported from outside of Canada. This conclusion is supported by our contact follow-up data, in which no case of MDR-TB was thought to be secondary to another, and our DNA fingerprint data, in which each of the archived MDR-TB isolates $(n=16)$ was determined to be unlike any of the others. The possibility that one or more of the four foreign-born patients who arrived in Canada before 1989 could have been infected in Canada, and then had reactivated TB during the time frame of the study was not excluded.

Although being foreign-born appears to be a risk factor for having an MDR initial isolate in Alberta and British Columbia, foreign-born status was not found to be a risk factor for MDR-TB in the United States (14). However, it is important to note that the epidemiology of MDR-TB in the United States has been strongly influenced by outbreaks of MDR-
TABLE 4

Treatment outcome of multidrug-resistant tuberculosis (TB) cases in Alberta and British Columbia (1989 to 1998)

\begin{tabular}{lc}
\hline Outcome & Number of cases (\%) \\
\hline Cured & $8(33)$ \\
Died & \\
$\quad$ TB-primary & $2(8)$ \\
TB-contributory & $3(13)$ \\
$\quad$ TB-unrelated & 0 \\
Transferred out & $4(17)$ \\
Other & $7(29)$ \\
\hline
\end{tabular}

TB among HIV-seropositive patients, particularly in New York City $(7,15)$. Of 173 patients with MDR-TB reported from New York City between 1983 and 1993, over half were known to be HIV infected, and over half gave no history of prior treatment, suggesting that person-to-person transmission of MDR strains was a major feature of the epidemic in that city (15). In selected metropolitan sites outside of New York City, most patients with MDR-TB had received prior TB treatment, were born outside the United States, and were not known to be HIV infected (16). In Alberta and British Columbia, there was no evidence that HIV seropositivity influenced the prevalence of MDR-TB. Of those tested $(n=17)$, only one patient was determined to be HIV seropositive, and the patient was not associated with any secondary cases.

Two studies from western Canada found that drugresistance in the foreign born is significantly higher in recent versus late arrivals $(4,6)$. Of the 20 foreign-born MDR-TB patients reported in Alberta and British Columbia between 1989 and 1998, 70\% had arrived within the past five years.

Not surprisingly, two-thirds of the MDR-TB patients had 'acquired' drug resistance; prior use of antituberculous drugs is a recognized risk factor for drug resistance $(5,14)$. Because immigrants to Canada with a past history of TB are automatically targeted for postlanding surveillance, a much larger proportion of the foreign-born MDR-TB patients were surveillance referrals ( $35 \%$ ) than is usual for the overall population of immigrants to Canada (5\%) (data from Citizenship and Immigration Canada).

MDR-TB duration of treatment and mortality were significant; to date only eight patients, each of whom required two years or more of antituberculous drug therapy, are cured, while six continue to be treated. Of the remaining patients, four have transferred out of Alberta and British Columbia, one refuses further treatment, and five (21\%) died with TB as a primary or contributory cause of death. In those in whom it was possible to make the determination, the average time to culture conversion was 134 days, considerably longer than average for smear-positive pulmonary TB due to drug susceptible isolates, 32 days (17). Four patients underwent resectional surgery to facilitate cure (18). The MDR-TB mortality rate exceeded that reported for TB in the Canadian population (5\%) (19), but was comparable with most other 
series of MDR-TB in HIV-seronegative patients from industrialized countries $(15,20-22)$. The financial burden of treating MDR-TB is known to be considerable (23); at an average of $\$ 1,152.00 /$ day, and an average length of stay of three months, the hospital costs alone of treating our patients averaged \$103,680.00.

Although no secondary case of MDR-TB was reported during the period of the study, most of the reported MDR-TB cases $(67 \%)$ were pulmonary and smear positive, increasing the likelihood that transmission of resistant strains to others may have taken place. In this regard, at least 10 contacts were known to have converted their tuberculin test and, thus, constitute a residual pool of MDR-TB infected Canadians who are at risk to develop reactivation MDR-TB in the future. A high proportion of other contacts were tuberculin positive with unknown converter status. Although some of these might, in fact, have been converters, this high number of positives among contacts probably reflects the fact that most of the patients and contacts were foreign born.

In Alberta and British Columbia, drug resistance should be suspected in all foreign-born TB patients, and MDR-TB

\section{REFERENCES}

1. Pablos-Méndez A, Raviglione M, Laszlo A, et al. Global surveillance for antituberculosis-drug resistance, 1994-1997. N Engl J Med 1998;338:1641-9

2. Eidus L, Jessamine A, Hershfield E, Helbecque D. A national study to determine the prevalence of drug resistance in newly discovered previously untreated tuberculosis patients, as well as in retreatment cases. Can J Public Health 1978;69:146-53.

3. Rivest P, Tannenbaum T, Bédard L. The epidemiology of tuberculosis in Montreal. Can J Public Health. (In press)

4. Long R, Manfreda J, Mendella L, Wolfe J, Parker S, Hershfield E. Antituberculous drug resistance in Manitoba from 1980-89. CMAJ 1993;148:1489-95.

5. Long R, Fanning A, Cowie R, Hoeppner V, FitzGerald M, and the Western Canada Tuberculosis Group. Antituberculous drug resistance in Western Canada (1993-1994). Can Respir J 1997;4:71-5.

6. Manns B, Fanning A, Cowie R. Antituberculous drug resistance in immigrants to Alberta, Canada, with tuberculosis, (1982-94). Int J Tuberc Lung Dis 1997;1:255-30.

7. Iseman M. Treatment of multidrug-resistant tuberculosis. N Engl J Med 1993;329:784-91.

8. Korzeniewska-Kosela M, FitzGerald M, Vedal S, et al. Spectrum of tuberculosis in patients with HIV infection in British Columbia: report of 40 cases. CMAJ 1992;146:1927-34.

9. Phair J, Wolinsky S. Diagnosis of infection with human immunodeficiency virus. Clin Infect Dis 1992;15:13-6.

10. van Embden J, Cave M, Crawford J, et al. Strain identification of Mycobacterium tuberculosis by DNA fingerprinting: recommendations for a standard methodology. J Clin Microbiol 1993;31:406-9.

11. Felsenstein J. Phylogenetics from molecular sequences: inference and reliability. Ann Rev Genet 1988;22:521-65.

12. Long R, Nobert E, Chomyc S, et al. Transcontinental spread of multidrug-resistant $M$ bovis. Am J Respir Crit Care Med (In press). should be suspected in recently arrived immigrants from the western Pacific region, especially those with a past history of antituberculous drug use in their country of origin. The latter should be started on all five first-line drugs until drug susceptibility tests allow for a more individualized regimen. Given that our MDR cases were resistant to an average of 3.25 first-line drugs, even this may not ensure that at least two of the drugs are effective when the bacterial population is large. Accordingly, drug susceptibility testing must always be provided, the results acted upon promptly, and the clinical, radiographic and mycobacteriological response to treatment closely monitored.

ACKNOWLEDGEMENTS: We thank Jean Fraser and Mabel Rodriguez of the British Columbia Centre for Disease Control, Shirley Chorney of Alberta Health, Disease Control and Prevention Branch, Sylvia Chomyc of the Provincial Laboratory of Public Health, Alberta, and Dr Neil Heywood of Citizenship and Immigration, Canada, for their expert technical assistance. We also thank Dr Mark FitzGerald for his helpful comments, as well as Dr Jure Manfreda for his review and Susan Falconer for her preparation of the manuscript.

13. Small P, Hopewell P, Singh S, et al. The epidemiology of tuberculosis in San Francisco: a population-based study using conventional and molecular methods. N Engl J Med 1994;330:1703-9.

14. Moore M, Onorato I, McCray E, Castro K. Trends in drug resistant tuberculosis in the United States, 1993-1996. JAMA 1997;278:833-7.

15. Park M, Davis A, Schluger N, Cohen H, Rom W. Outcome of MDR-TB patients, 1983-1993: prolonged survival with appropriate therapy. Am J Respir Crit Care Med 1996;153:317-24.

16. Gordin F, Nelson E, Matts J, et al. The impact of human immunodeficiency virus infection on drug resistant tuberculosis. Am J Respir Crit Care Med 1996;154:1478-83.

17. Telzak E, Fazel B, Pollard C, Turett G, Justman J, Blum S. Factors influencing time to sputum conversion among patients with smear-positive pulmonary tuberculosis. Clin Infect Dis 1997;25:666-70.

18. Pomerantz M, Madsen L, Goble M, Iseman M. Surgical management of resistant mycobacterial tuberculosis and other mycobacterial pulmonary infections. Ann Thorac Surg 1991;52:1108-12.

19. Enarson D, Grzybowski S, Dorken E. Failure of diagnosis as a factor in tuberculosis mortality. CMAJ 1978;118:1520-2.

20. Goble M, Iseman M, Madsen L, Waite D, Ackerson L, Horsburgh C Jr. Treatment of 171 patients with pulmonary tuberculosis resistant to isoniazid and rifampin. N Engl J Med 1993;328:527-32.

21. Telzak A, Sepkowitz K, Alpert P, et al. Multidrug resistant tuberculosis in patients without HIV infection. N Engl J Med 1995;333:907-11.

22. Geerligs W, van Altena R, van der Werf T. Anti-tuberculosis drug resistance. N Engl J Med 1998;339:1079-80. (Lett)

23. Mahmoudi A, Iseman M. Pitfalls in the care of patients with tuberculosis. JAMA 1993;270:65-8. 


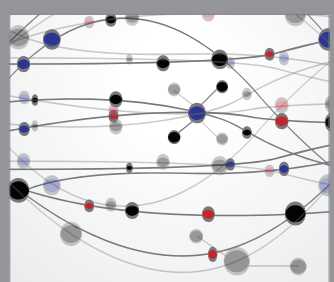

The Scientific World Journal
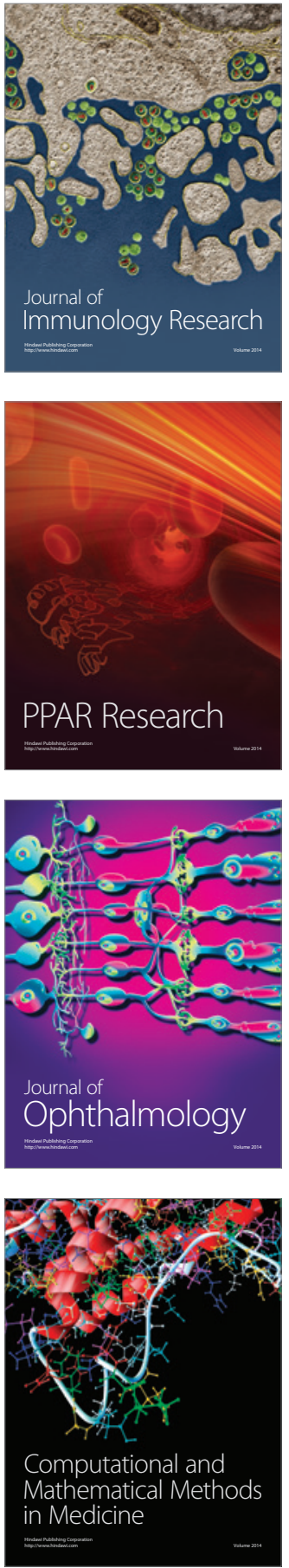

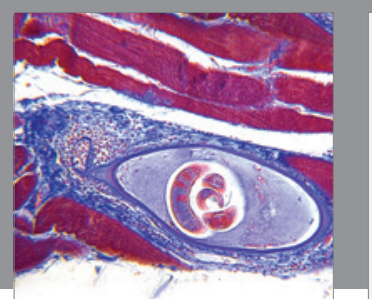

Gastroenterology Research and Practice

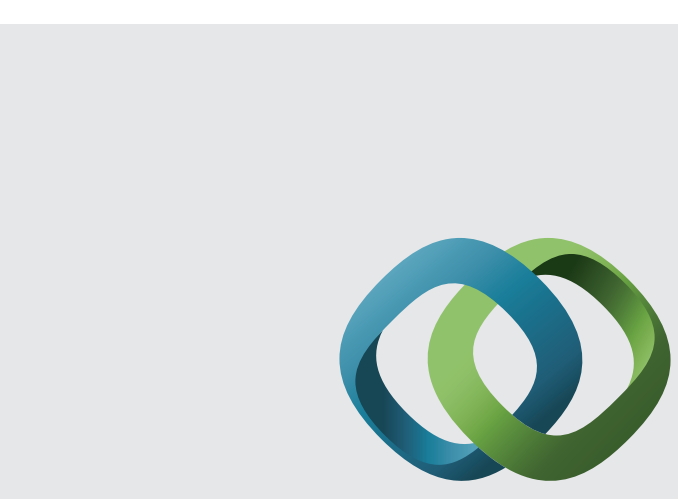

\section{Hindawi}

Submit your manuscripts at

http://www.hindawi.com
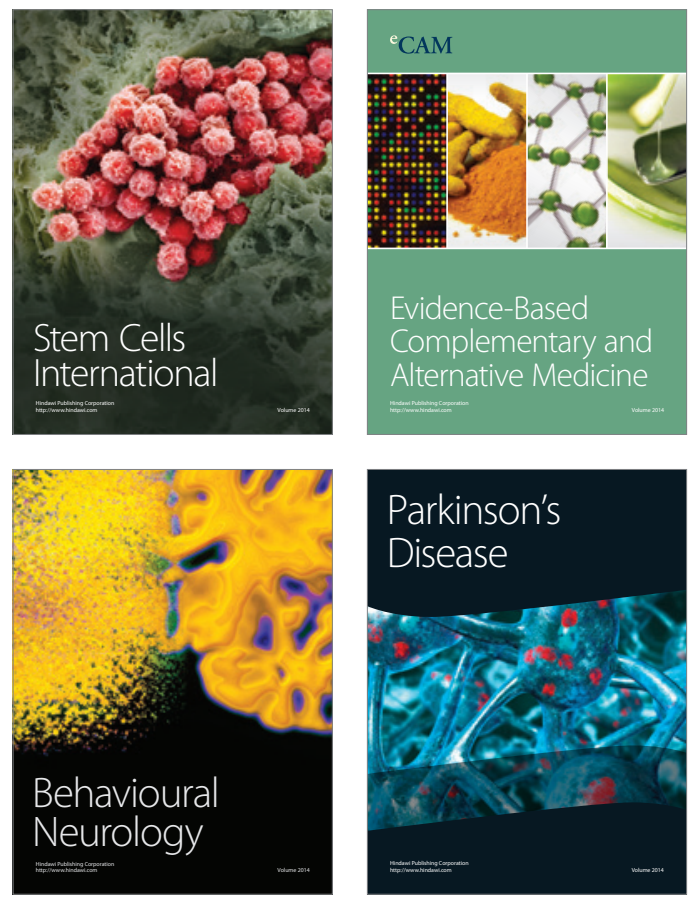
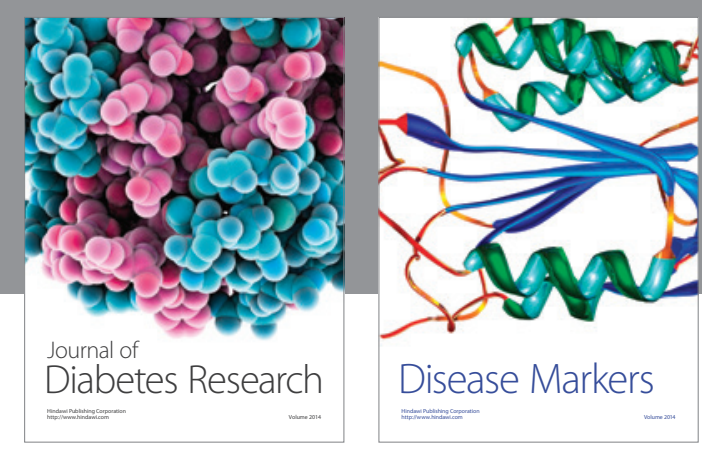

Disease Markers
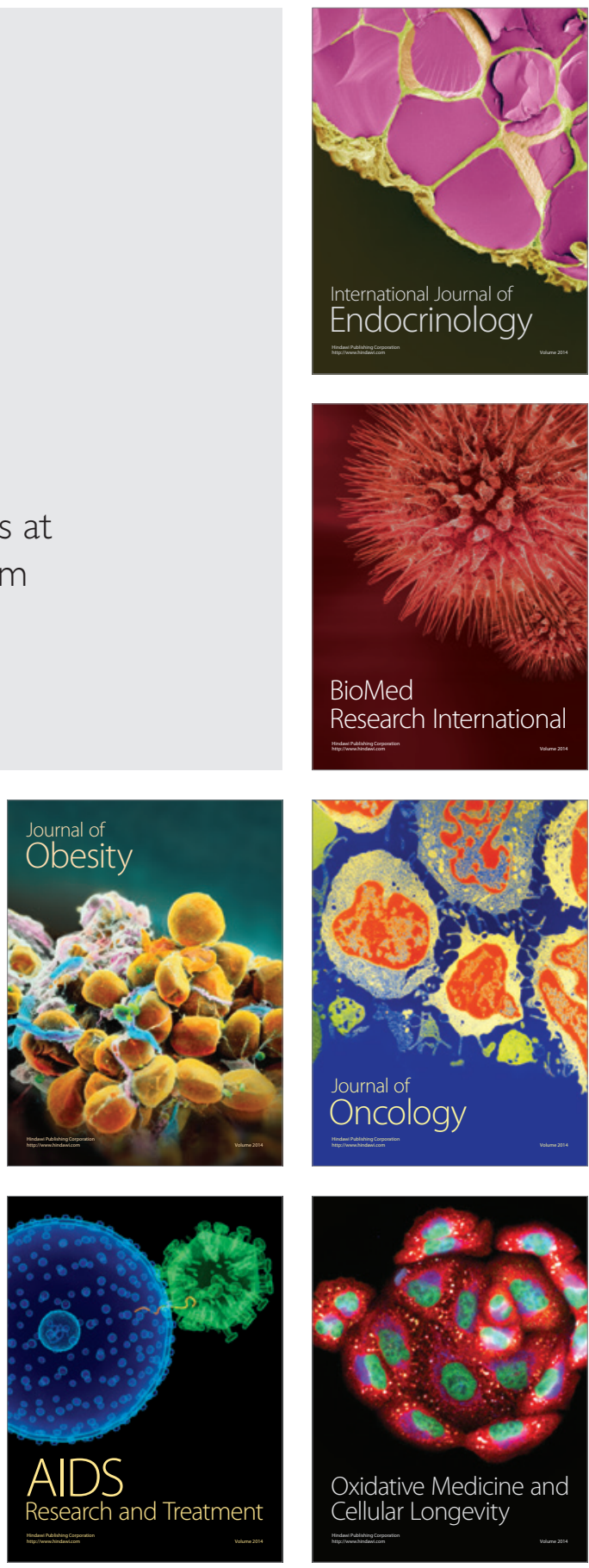